\title{
ADSORPTION OF DODECYLBENZENESULFONIC ACID ON THE ALUMINA PARTICLES IN THE PREPARATION OF ALUMINA FOAM
}

\author{
\#ZORA HAJDÚCHOVÁ*, LADISLAV PACH*, JÁN LOKAJ*,** \\ *Faculty of Chemical and Food Technology, Slovak Technical University, Radlinského 9, Bratislava, Slovakia \\ **Faculty of Material Science and Technology, Slovak Technical University, Jána Bottu 2781/25,Trnava, Slovakia \\ "E-mail: zora.hajduchova@stuba.sk
}

Submitted October 12, 2017; accepted January 2, 2018

Keywords: Adsorption, Alumina foam, Dodecylbenzenesulfonic acid, Suspension $\mathrm{pH}$, Sintering temperature

\begin{abstract}
Partially hydrophobized particles of $\alpha-\mathrm{Al}_{2} \mathrm{O}_{3}$ were used to prepare the alumina foams. Dodecylbenzenesulfonic acid (DBSA) was applied to the hydrophobized surface of alumina particles. The infrared spectroscopy provided the evidence of the interaction (adsorption) of DBSA on the alumina surface. The quantity of DBSA adsorbed on the alumina particles was determined using Lambert-Beer law by measuring UV-VIS spectra. The mechanisms of DBSA adsorption on the surface of alumina particles may be attributed to (1) electrostatic interactions or (2) specific chemical reactions between the surfactant and the surface hydroxyl groups. Adsorption of DBSA on the alumina particles is strongly influenced by the pH of suspensions. The quantity of DBSA is not sufficient to hydrophobize alumina particles at $p H$ up to about $p H$ 9.5, as the electrostatic repulsion forces between the sulfonic group of DBSA and the alumina surface prevailed and the DBSA acts only as a surfactant. The foams were sintered at $1400,1450,1500,1550$ and $1600^{\circ} \mathrm{C}$. The optimal sintering temperature was found to be $1550^{\circ} \mathrm{C}$. The maximal compressive strength of the alumina foams was $\sim 300 \mathrm{kPa}$ while its porosity was relatively high $(96.7 \%)$.
\end{abstract}

\section{INTRODUCTION}

Adsorption of a surfactant onto particle surface plays an important role to prepare particle stabilized foams by direct foaming method. The aim of the adsorption of amphiphilic molecules of the surfactant onto particles is to hydrophobize the surface of the particles. These partially hydrophobized particles are adsorbed onto the air-water interface of bubbles creating a steric barrier to the coalescence. These solid particles with tailored surface chemistry stabilize the gas bubbles. The nature of the solid surface that is either hydrophobic or hydrophilic and the electrical interactions play an important role in the kinetics of adsorption of surfactant at the solid-liquid interface $[1,2]$. The surfactants are classified according to the polar head group. A non-ionic surfactant has no charged groups in its head. An anionic surfactant has negatively charged groups and the cationic one has positively charged ones. Dodecylbenzenesulfonic acid is a common, synthetic anionic surfactant with negatively charged sulfonate head $\left(-\mathrm{SO}_{3}{ }^{-}\right)$. There are not many papers dealing with the adsorption kinetic of DBSA on the particle surface - water interface unlike the considerable amount of papers that have been dealt with on the adsorption characteristics of the similar anionic surfactant SDS (sodium dodecyl sulfate) onto various oxides [3-6]. The strong adsorption ability of SDS on alumina particles allows the preparation of ultra- stable wet foams in very wide $\mathrm{pH}$ range (from 4.0 to 9.0) [6]. Adsorbed mass of SDS consistently decreased with increasing $\mathrm{pH}[3,6]$. The adsorption ability of the surfactant is influenced by different parameters such as molecular structure (the surfactant type), surface charge, ionic strength, temperature, additives [2, 6-9].

The aim of this work is to reveal the interaction of dodecylbenzenesulfonic acid with the alumina surface and to study the quantity of DBSA adsorbed on the alumina particles. Effect of the $\mathrm{pH}$ value on the adsorption ability of DBSA and alumina foam properties have been investigated. In order to prepare the stable alumina foam, the optimal $\mathrm{pH}$ region and sintering temperature were thus determined. The effect of DBSA quantity on the properties of alumina foams was recently reported by us [10].

\section{EXPERIMENTAL}

\section{Materials}

The high purity $\alpha$-alumina (MARTOXID ${ }^{\circledR}$ MR70) used in this investigation was kindly supplied by Martinswerk $\mathrm{GmbH}$, Germany. The average particle size was $500 \mathrm{~nm}$ with the specific surface area of $10 \mathrm{~m}^{2} \cdot \mathrm{g}^{-1}$. Dodecylbenzenesulfonic acid (DBSA, $\geq 95 \%$ mixture of isomers, SIGMA-ALDRICH GmbH, Germany) was used as an anionic surfactant. Analytical grade $\mathrm{NaOH}$ and $\mathrm{HNO}_{3}$ were used to adjust $\mathrm{pH}$ value of the system. 


\section{Sample preparation}

The alumina (30 wt. \%), distilled water, DBSA $(0.15$ wt. $\%)$ and $\mathrm{pH}$ adjusting agent $\left(\mathrm{NaOH}, \mathrm{HNO}_{3}\right)$ were thoroughly stirred for $3 \mathrm{~min}$. The foaming of suspensions was carried out using a laboratory mixer at the mixing velocity of cca. $800 \mathrm{rpm}$ for $30 \mathrm{~s}$. All foams were dried out at ambient temperature for $48-72 \mathrm{~h}$. The sintering of dried foams was performed in an electrical furnace in two steps. In the first step, dried foams were sintered for $30 \mathrm{~min}$ at $900^{\circ} \mathrm{C}$ with the heating rate of $5^{\circ} \mathrm{C} \cdot \mathrm{min}^{-1}$ and in the second one for $1 \mathrm{~h}$ at 1400,1450 , 1500,1550 and $1600^{\circ} \mathrm{C}\left(10^{\circ} \mathrm{C} \cdot \mathrm{min}^{-1}\right)$.

\section{Characterization}

The interaction of $\alpha$-alumina with dodecylbenzenesulfonic acid has been investigated by infrared spectroscopy (FTIR Spectrometer Nicolet 5700). The KBr pellet technique was utilized to prepare samples for the IR studies. IR spectroscopic studies were carried out on the alumina and DBSA samples before interaction as well as those obtained after adsorption.

The zeta potential of dilute aqueous alumina suspension $(0.4 \mathrm{wt}$. \%) solid was measured by microelectrophoresis with a zeta sizer (Model Zetasizer 3000HSA, Malvern). Determination of the point of zero charge was carried out by determining the zeta potential at a range of $\mathrm{pH}$ values. An Inolab $730 \mathrm{pH}$ meter (MARCONI) was used to determine the $\mathrm{pH}$ value of the suspensions.

The absorbance is proportional to the concentrations according to Lambert-Beer law. The solutions with different mass concentrations of DBSA $\left(0.4-2.4 \mathrm{~g} \cdot \mathrm{dm}^{-3}\right)$ were prepared. The quantity of DBSA adsorbed on the alumina particles was determined by calculating the difference between the initial DBSA concentration and the residual concentration in the supernatant. The clear supernatant was removed and analyzed for residual DBSA concentration using the UV-Vis spectrophotometer (Helios $\alpha$, UNICAM). To determine the quantity of adsorbed DBSA on the alumina particles it was necessary to obtain the solution from the wet foam. First, filtration of the foam was carried out under reduced pressure and in the second step, the solution was centrifuged (Universal 30F, Hettich, Germany) for $15 \mathrm{~min}$ at $8000 \mathrm{rpm}$ to separate the alumina particles from aqueous suspension. Maximum absorbance was reached at $\lambda=260 \mathrm{~nm}$. In order to quantitatively assess the DBSA concentration, a linear calibration curve was constructed at a wavelength of $260 \mathrm{~nm}$. The equation expressing the linear dependence was absorbance is equal to mass concentration of DBSA $\left(\mathrm{g} \cdot \mathrm{dm}^{-3}\right)$.

The foam ratio $\mathrm{K}_{\mathrm{F}}$ was calculated from the foam volume-to-initial volume of the system. The bulk density was determined from the weight-to-volume ratio. The porosity was calculated using the equation: $P=\left(\rho_{t}-\rho_{b}\right) / \rho_{t} \times 100 \%$ where $\rho_{t}$ is the theoretical density $\left(3980 \mathrm{~kg} \cdot \mathrm{m}^{-3}\right)$ and $\rho_{b}$ is the bulk density of the alumina foam. The linear shrinkage of foams was determined from the dimensions of the foams before drying and after the sintering process. Compressive strength measurements were performed using a universal testing machine (Hegewald \& Peschke, Nossen, Germany). Samples were crushed under compression of $5 \mathrm{~mm} \cdot \mathrm{min}^{-1}$. The microstructure was observed by scanning electron microscopy (SEM, TESLA BS 300).

\section{RESULTS AND DISCUSSION}

The adsorption of dodecylbenzenesulfonic acid on the alumina surface

The IR spectrum of $\alpha$-alumina is shown in Figure 1. The absorption peaks at 641, 604, 488 and $457 \mathrm{~cm}^{-1}$ are typically for the IR spectrum of $\alpha$-alumina [11]. The weak peaks at 1630 and $3442 \mathrm{~cm}^{-1}$ are due to the presence of hydroxyl groups and moisture in the sample [11].

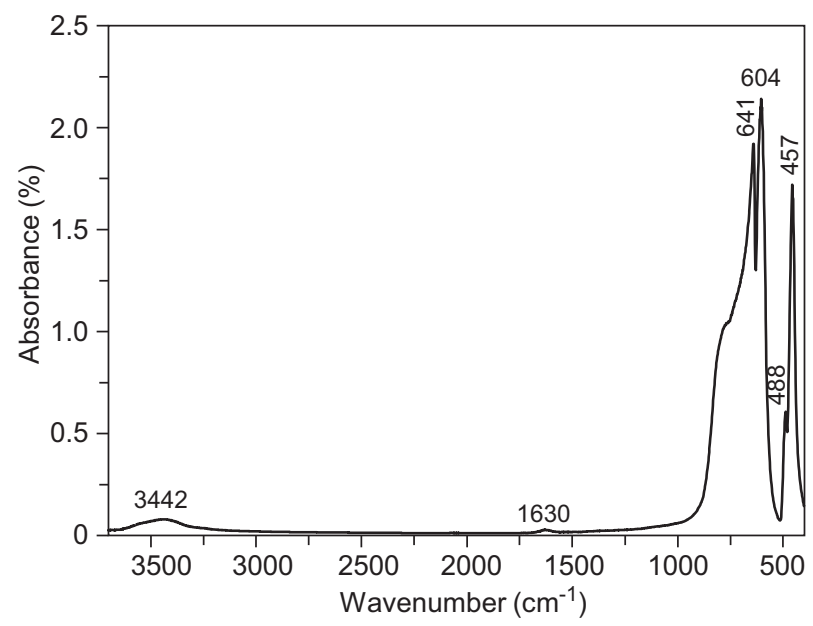

Figure 1. IR spectrum of $\alpha$-alumina.

The IR spectrum of dodecylbenzenesulfonic acid (DBSA) is shown in Figure 2. The $\mathrm{C}-\mathrm{H}$ stretching vibrations for methyl and methylene are the most characteristic in terms of organic compound containing long aliphatic chain. The stretching modes of methyl and methylene groups occur in the $3000-2800 \mathrm{~cm}^{-1}$ region. The $\mathrm{C}-\mathrm{H}$ asymmetric/symmetric stretching vibrations of methyl group occur at $2959 \mathrm{~cm}^{-1}, 2872 \mathrm{~cm}^{-1}$ and the $\mathrm{C}-\mathrm{H}$ asymmetric/symmetric stretching vibrations of methylene groups occur at $2922 \mathrm{~cm}^{-1}, 2853 \mathrm{~cm}^{-1}$ [12]. Two peaks at 1465 and $1377 \mathrm{~cm}^{-1}$ are assigned to the $\mathrm{C}-\mathrm{H}$ bending vibrations of methylene as well as to the methyl group [12]. The characteristic absorption peaks of benzene ring are observed in the $3100-3000 \mathrm{~cm}^{-1}$ and in the $1600-1400 \mathrm{~cm}^{-1}$ regions. The $\mathrm{C}-\mathrm{H}$ stretching vibrations of the benzene ring appear at $3066,3028 \mathrm{~cm}^{-1}$ and the $\mathrm{C}-\mathrm{C}$ stretching vibrations of the benzene ring appear at 1601 and $1495 \mathrm{~cm}^{-1}$ [12]. The $\mathrm{C}-\mathrm{H}$ out-ofplane bending vibration is at $728 \mathrm{~cm}^{-1}$. 


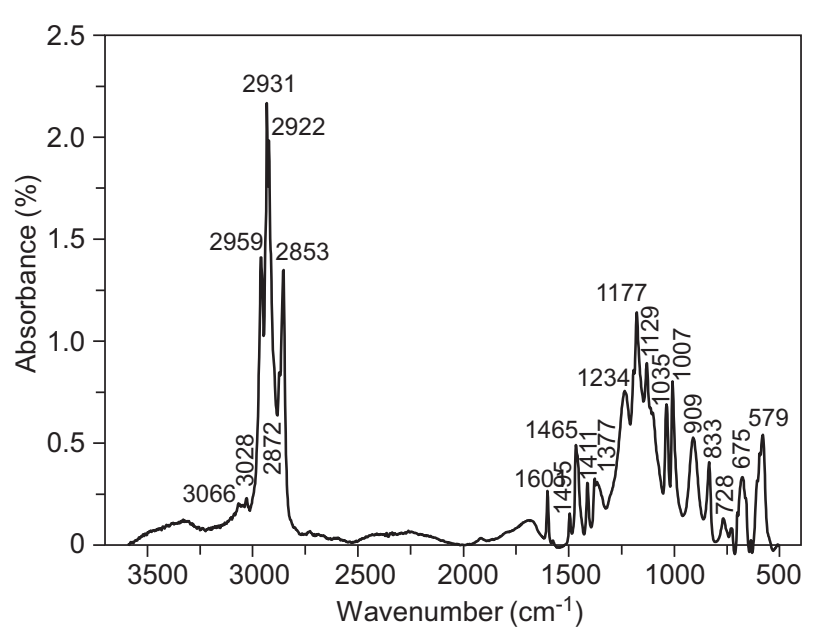

Figure 2. IR spectrum of DBSA.

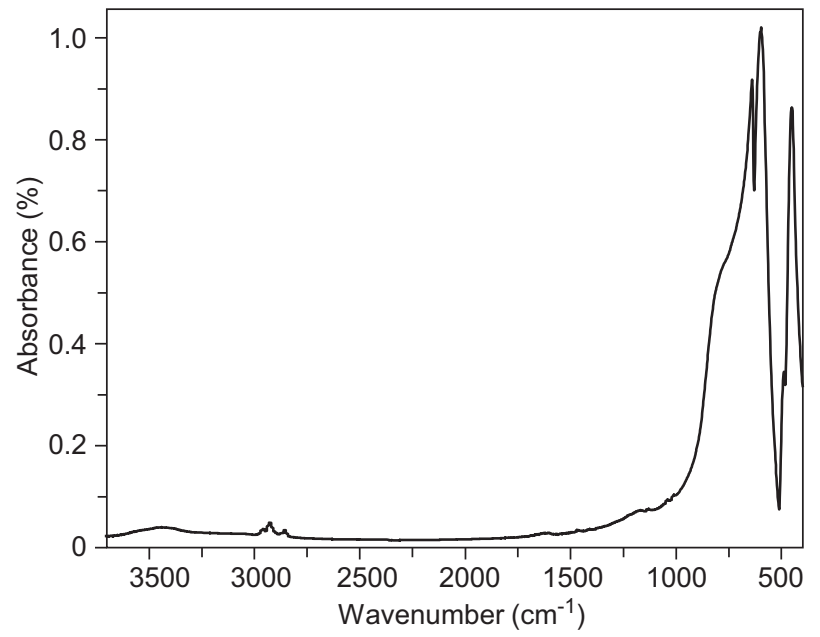

Figure 3. IR spectrum of alumina - DBSA system.

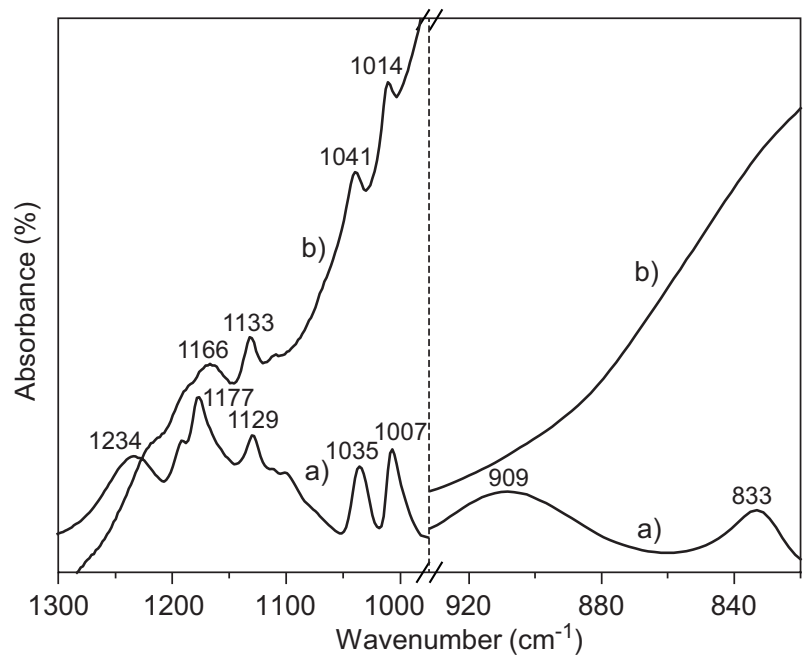

Figure 4. IR spectrum of DBSA (a), alumina - DBSA system (b), focused areas: $1300-980 \mathrm{~cm}^{-1}, 940-820 \mathrm{~cm}^{-1}$.
The stretching modes of the sulfonic acid functional group $-\mathrm{SO}_{3} \mathrm{H}$ occur in the region of $1200-1000 \mathrm{~cm}^{-1}$. The asymmetric stretching vibrations of sulfonic group occur at $1177 \mathrm{~cm}^{-1}, 1129 \mathrm{~cm}^{-1}$ and the symmetric stretching vibrations of sulfonic group occur at $1035 \mathrm{~cm}^{-1}$, $1007 \mathrm{~cm}^{-1}[13,14]$. The peak at $579 \mathrm{~cm}^{-1}$ is assigned to the bending vibration of this group [13]. The $\mathrm{O}-\mathrm{H}$ inplane bending vibration is at $1234 \mathrm{~cm}^{-1}[15,16]$. The $\mathrm{O}-\mathrm{H}$ out-of-plane bending vibrations are at 833 and $909 \mathrm{~cm}^{-1}[15,16,17,18]$.

The IR spectrum of alumina obtained after adsorption of DBSA is shown in Figure 3. The Figure 4 shows the IR spectra of DBSA and alumina - DBSA system in ranges $1300-980 \mathrm{~cm}^{-1}$ and $940-820 \mathrm{~cm}^{-1}$. These areas elucidate the way of interaction (adsorption) of DBSA on the alumina surface.

The peaks at 1177,1129 and $1035,1007 \mathrm{~cm}^{-1}$ due to asymmetric/symmetric stretching vibrations of sulfonic group are slightly enhanced and appear at 1166, 1133 and $1041,1014 \mathrm{~cm}^{-1}$ in the alumina - DBSA system.

The absorption bands at 1234, 909 and $833 \mathrm{~cm}^{-1}$ are located only in the DBSA, whereas these peaks are absent in the alumina - DBSA system, as seen in Figure 4. These peaks are $\mathrm{O}-\mathrm{H}$ deformation vibrations of sulfonic group. The shift of adsorption peaks of sulfonic group and absence of hydrogen bonding after adsorption, indicate interaction of the sulfonic group with the alumina surface. The interaction is accompanies with the deprotonation of the $\mathrm{SO}_{3} \mathrm{H}$ group.

The absorbance increased from 0.610 to 1.07 for solutions with $\mathrm{pH}$ equal to 8.5 and 9.5 . The quantity of DBSA adsorbed on the alumina particles decreased from $75 \%$ to $55 \%$ when the $\mathrm{pH}$ solutions increased from 8.5 to 9.5 . The results obtained fit well with those given in [3].

The mechanisms of adsorption of dodecylbenzenesulfonic acid in an aqueous solution of the alumina particles

The surface properties of colloidal particles in aqueous media are determined by the protonation and deprotonation reactions of surface hydroxyl groups with $\mathrm{H}_{3} \mathrm{O}^{+}$and $\mathrm{OH}^{-}$ions from water.

The particle surfaces generally contain $\left(-\mathrm{OH}_{2}^{+}\right)$, $(-\mathrm{OH})$ and $\left(-\mathrm{O}^{-}\right)$groups according to the size of the zeta potential of the oxide [19]. Surfaces with positive net charge groups are typical for the alumina particles under acidic conditions, on the other hand, the predominance of negative net charge groups $\left(-\mathrm{O}^{-}\right)$are located on the alumina surface under alkaline conditions. The surface concentration of protonated hydroxyl group $\left(\mathrm{OH}_{2}^{+}\right)$ and deprotonated hydroxyl group $\left(\mathrm{O}^{-}\right)$are equal in the isoelectric point. Neutral net charge groups $(-\mathrm{OH})$ predominate on the surfaces of the alumina particles under slightly alkaline conditions [19]. 
Dodecylbenzenesulfonic acid (DBSA) is the strong organic acid. The sulfonic group is the functional group of DBSA which may be dependent on the conditions ( $\mathrm{pH}$, ionic strength) deprotonated $\left(\mathrm{SO}_{3}^{-}\right)$, respectively protonated $\left(\mathrm{SO}_{3} \mathrm{H}\right)$. The relative density of surface protonated and surface deprotonated groups is equal at $\mathrm{pH}=\mathrm{pKa}$ value of this functional group, which is equal to 1 . The sulfonic group of DBSA is almost completely deprotonated at a $\mathrm{pH}$ greater than 4 , which was used in this work.

The proposed mechanisms of adsorption of dodecylbenzenesulfonic acid in an aqueous solution of the alumina particles, is shown in Figure 5. The interactions are strongly dependent on the $\mathrm{pH}$ solutions.

Adsorption of acid to the surface of the alumina is generally due to the [19]:

- electrostatic interactions between the particle surface charge and the oppositely charged group of the acid,

- specific chemical reactions between the particle surface and the acid functional group.

For the alumina particles used during this study an isoelectric point of $\mathrm{pH}=8.9$ was determined by zeta potential measurement.

DBSA is an anionic surfactant which is strongly adsorbed on the surface of the alumina particles at $\mathrm{pH}$ lower than the isoelectric point unlike nonionic surfactants which are essentially not adsorbed in the vicinity of the isoelectric point of alumina [20].

The maximum degree of adsorption of dispersant is in the $\mathrm{pH}$ range corresponding to the $\mathrm{pKa}$ value of the functional group [21].
The positively charged surface of the alumina under acidic $\mathrm{pH}$ conditions could also have chemical interactions with the deprotonated sulfonic group of DBSA to form complex (Figure 5).

The density of surface deprotonated groups increases with the increase of the $\mathrm{pH}$ value and the electrostatic repulsive forces between the positively charged surfaces of the alumina particles and sulfonic group of DBSA are dominant.

Hydrogen bonding predominates over electrostatic interaction under slightly alkaline conditions.

\section{Properties of the alumina foam depending on $\mathrm{pH}$ suspension}

The measured and calculated properties of alumina foams were as follows, the foam ratio, bulk density, porosity and compressive strength. Figure 6 shows that the foam ratio and the bulk densities of alumina foams are strongly affected by the $\mathrm{pH}$ suspension. The foam ratio increases and bulk density of foams decreases with increasing $\mathrm{pH}$. It was found that for this system there is a particular $\mathrm{pH}$ range for preparing stable alumina foam. Increasing $\mathrm{pH}$ above 9.5, the foam ratio is too high thus leading to the destabilization mechanisms of the foam and it collapses. As shown in Figure 6, the foam ratio of the sample prepared at $\mathrm{pH} 9.5$ (marked by *) is equal 9 and thus the bulk density plot could not be drawn.

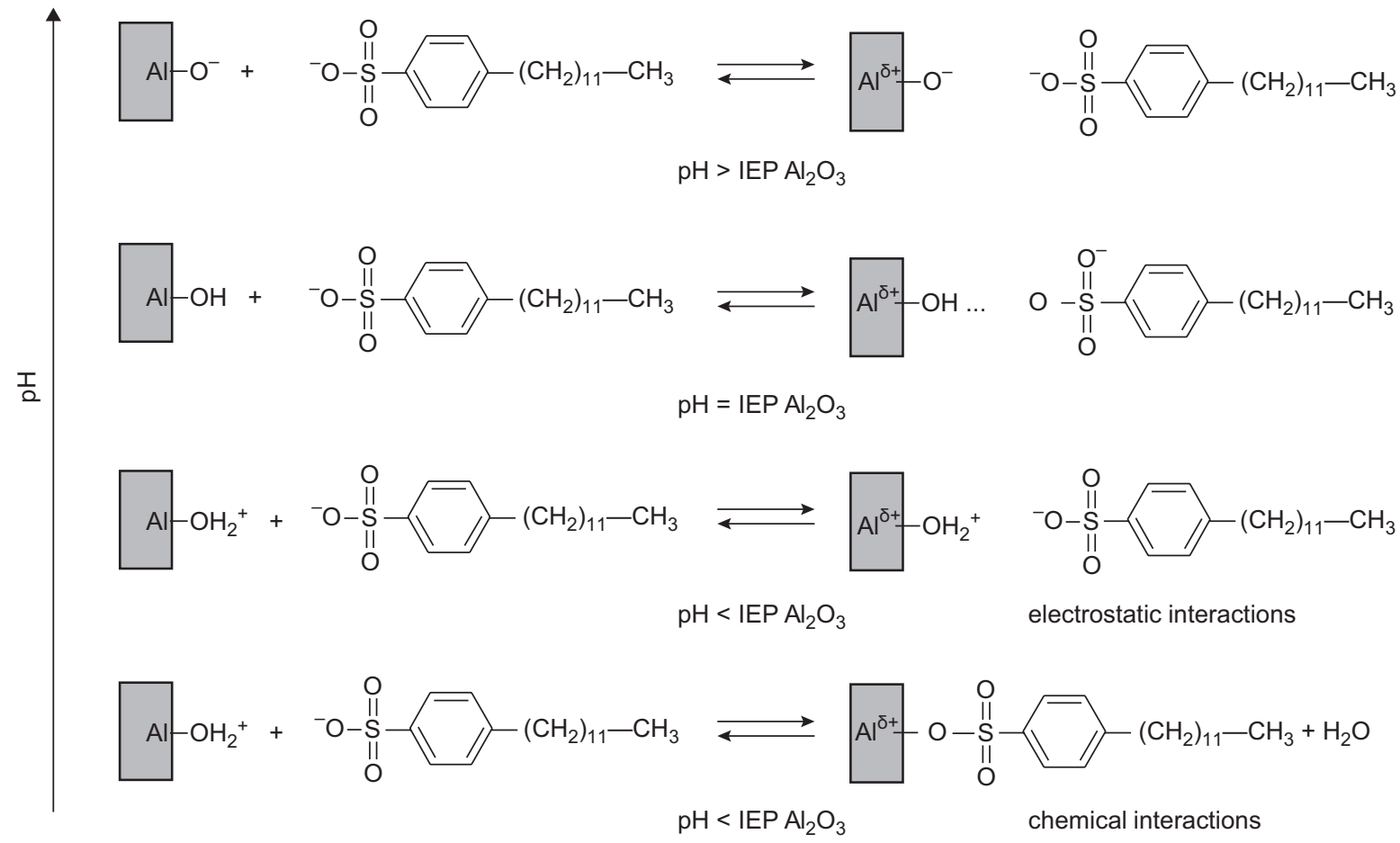

Figure 5. Proposed mechanisms of adsorption of dodecylbenzenesulfonic acid in an aqueous solution of Al2O3 particles (IEP isoelectric point). 


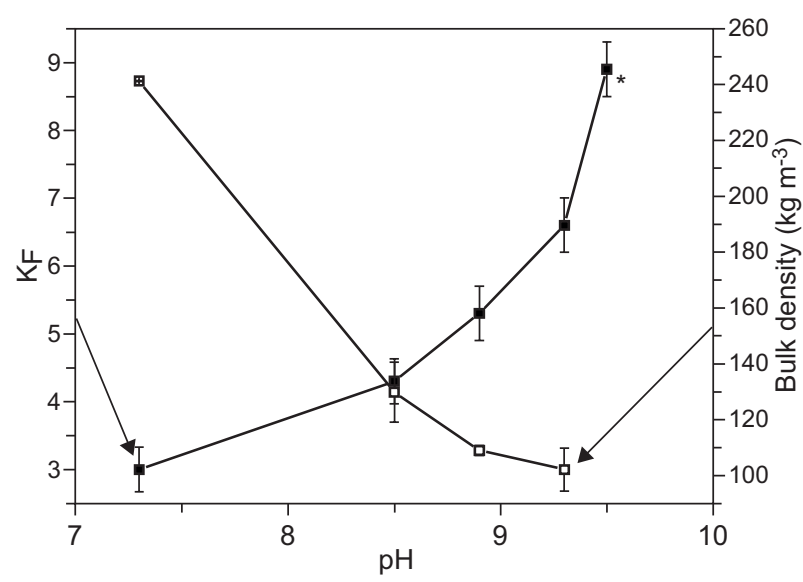

Figure 6. Effect of $\mathrm{pH}$ of the suspension on the foam ratio (KF) and on the bulk density of alumina foams.

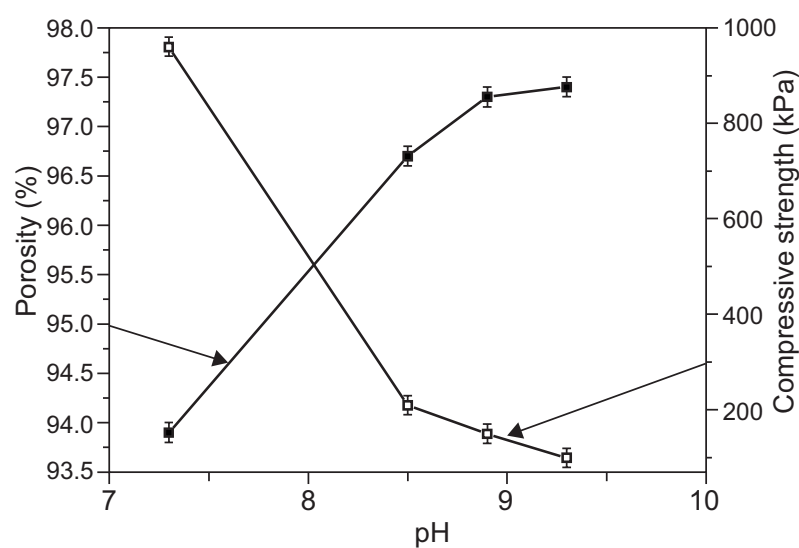

Figure 7. Effect of $\mathrm{pH}$ of the suspension on the porosity and on the compressive strength of alumina foams sintered at $1450^{\circ} \mathrm{C}$.

Figure 7 presents the porosity and the compressive strength data as a function of $\mathrm{pH}$. These properties are greatly influenced by the foam ratio and the bulk density of alumina foams. With increasing $\mathrm{pH}$ the amount of foam increases during foaming, bulk density decreases and thus, the porosity increases. Linear shrinkage was the same for all samples $(20 \% \pm 2)$ and the compressive strength decreases with increasing $\mathrm{pH}$, as shown in Figure 7.

\section{Properties of the ceramic foam depending on sintering temperature}

The linear shrinkage and porosity of alumina foams sintered to temperatures $1400,1450,1500,1550$ and $1600^{\circ} \mathrm{C}$ are shown in Figure 8. The linear shrinkage increases from $20.4 \%$ to $26.0 \%$ and the porosity decreases from $98.2 \%$ (bulk density is $72.5 \mathrm{~kg} \cdot \mathrm{m}^{-3}$ ) to $96.5 \%\left(139 \mathrm{~kg} \cdot \mathrm{m}^{-3}\right)$ on increasing sintering temperature from $1400^{\circ} \mathrm{C}$ to $1600^{\circ} \mathrm{C}$. The change of porosity between $1400^{\circ} \mathrm{C}$ and $1500^{\circ} \mathrm{C}$ is larger than others. The porosities of alumina foams decrease slightly when the sintering temperature is up to $1500^{\circ} \mathrm{C}$.

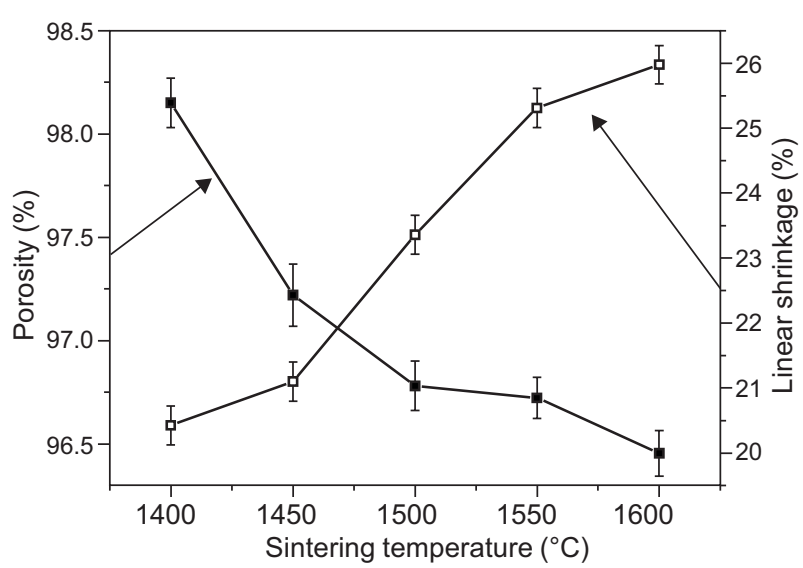

Figure 8. Porosity and linear shrinkage of alumina foams sintered at $1400,1450,1500,1550$ and $1600^{\circ} \mathrm{C}$.

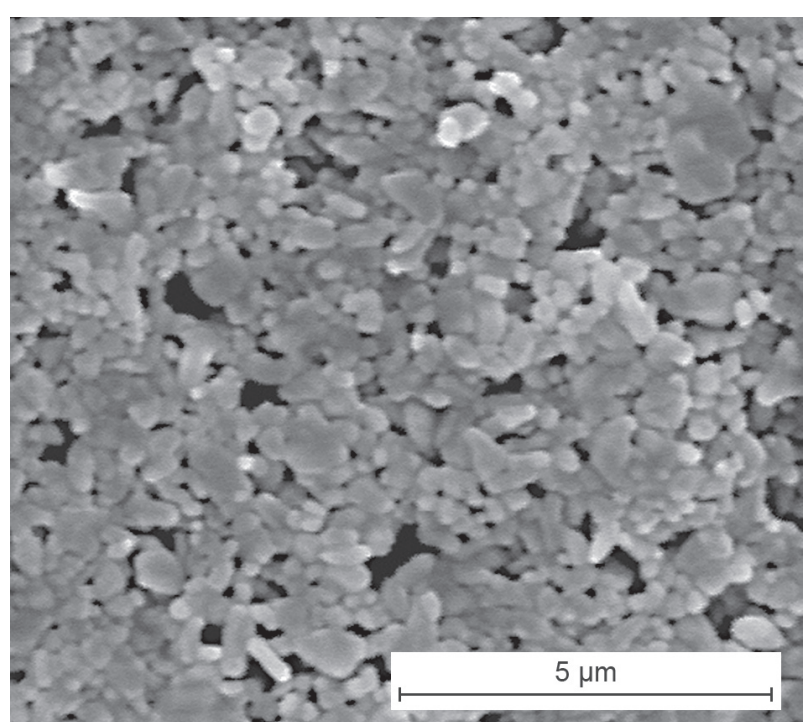

a) $1400^{\circ} \mathrm{C}$

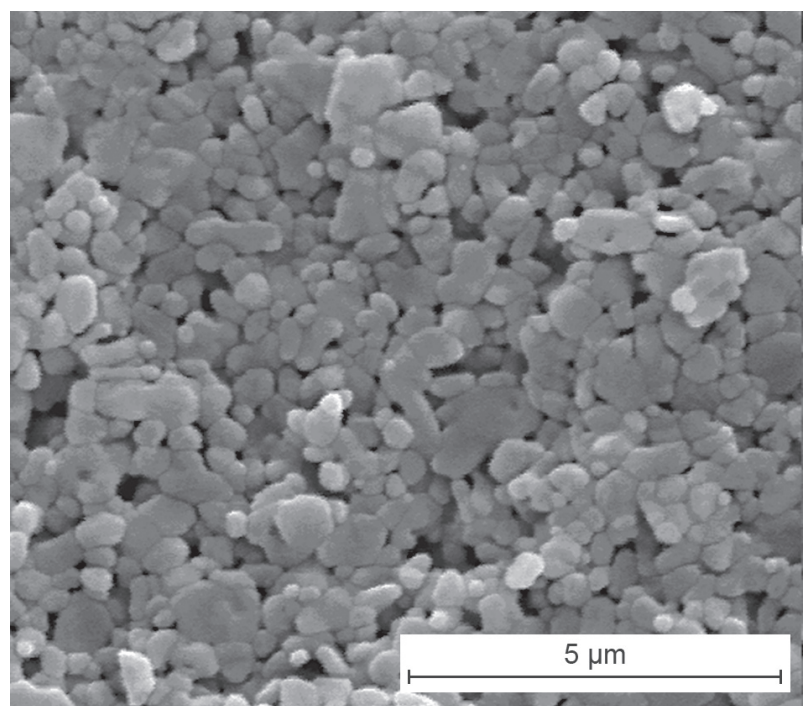

b) $1450^{\circ} \mathrm{C}$

Figure 9. SEM microstructure of alumina foams (scaffold) sintered at: a) $1400^{\circ} \mathrm{C}$, b) $1450^{\circ} \mathrm{C}$. (Continue on next page) 


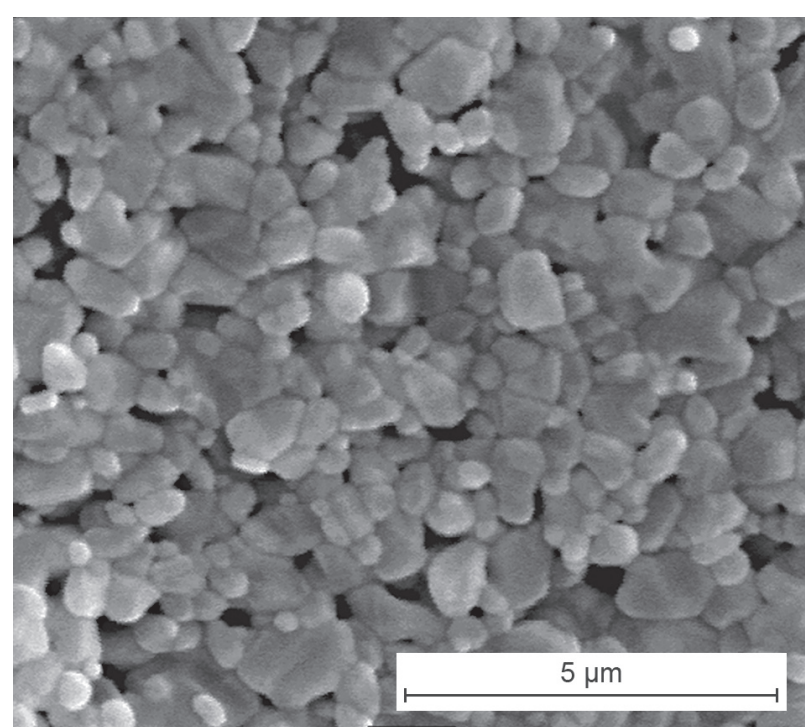

c) $1550^{\circ} \mathrm{C}$

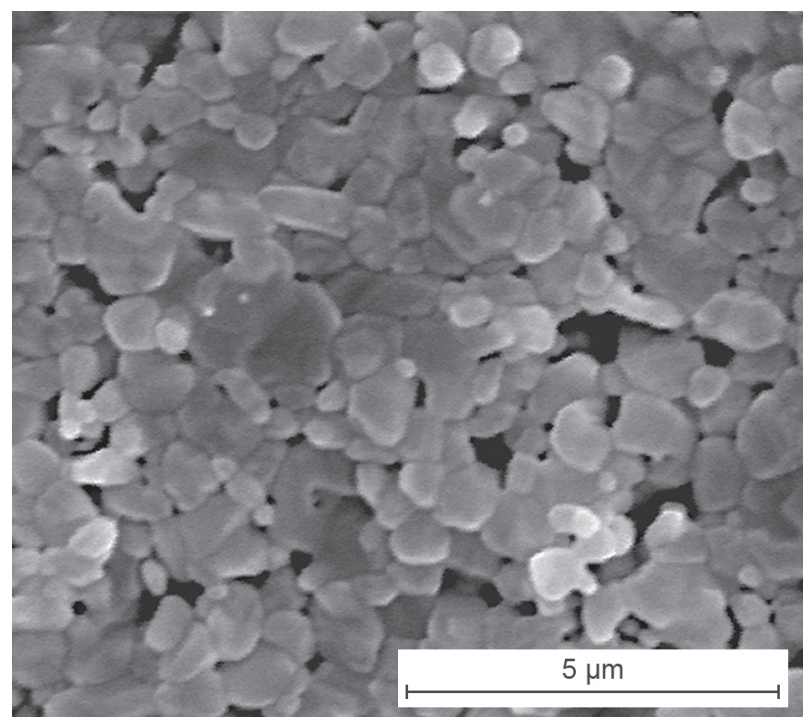

d) $1600^{\circ} \mathrm{C}$

Figure 9. SEM microstructure of alumina foams (scaffold) sintered at: c) $\left.1550^{\circ} \mathrm{C}, \mathrm{d}\right) 1600^{\circ} \mathrm{C}$.

Figure 9 shows the microstructure of alumina foams sintered at $1400-1600^{\circ} \mathrm{C}$ and figure 10 shows the arrangement of grains in the lamellas of sintered alumina foams. The grains of $\mathrm{Al}_{2} \mathrm{O}_{3}$ grow and turn into large grains with increasing sintering temperature of the foams. Thus, the result is decreasing of samples porosities. When the sintering temperature is up to $1550^{\circ} \mathrm{C}$ a few grains grow to larger dimensions compared to that of other grains.

The porosity and grains contacting area are two key factors affecting the strength of alumina foams [22]. On increasing the sintering temperature the compressive strength increases until it reaches the maximal value and then slightly decreases, as shown in Figure 11. The maximal value of compressive strength is at temperature of $1550^{\circ} \mathrm{C}$, which is in good agreement with article by Han et al [22].

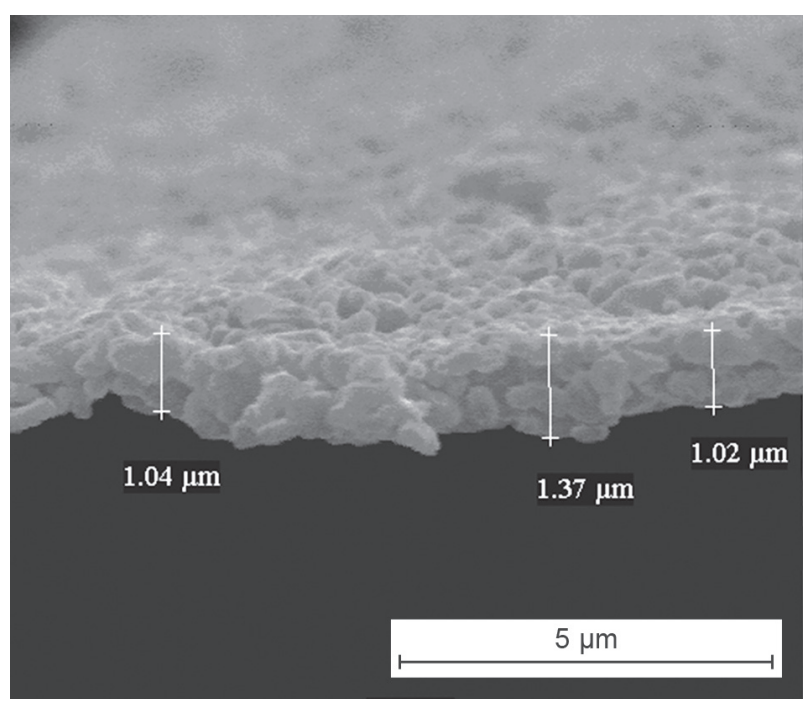

a) $1550^{\circ} \mathrm{C}$

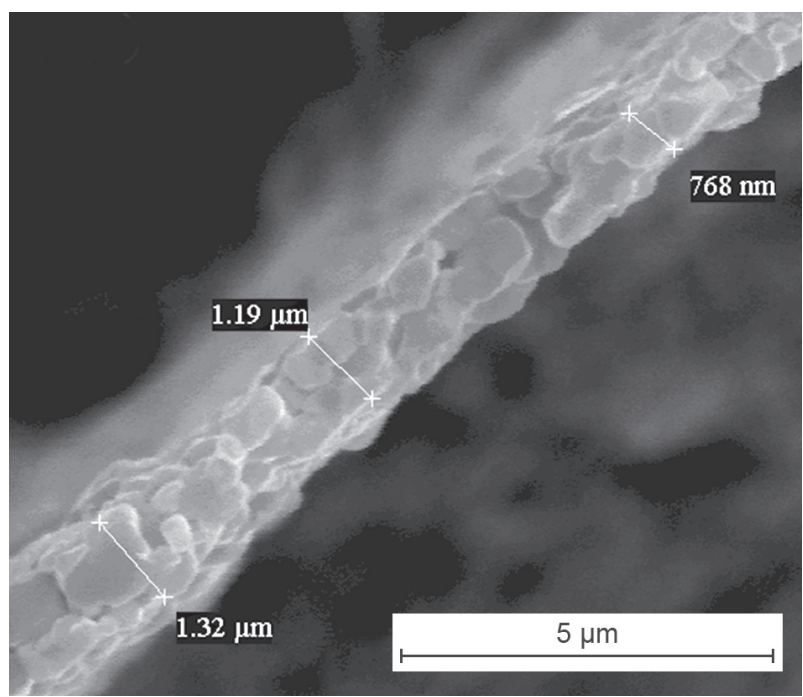

b) $1550^{\circ} \mathrm{C}$

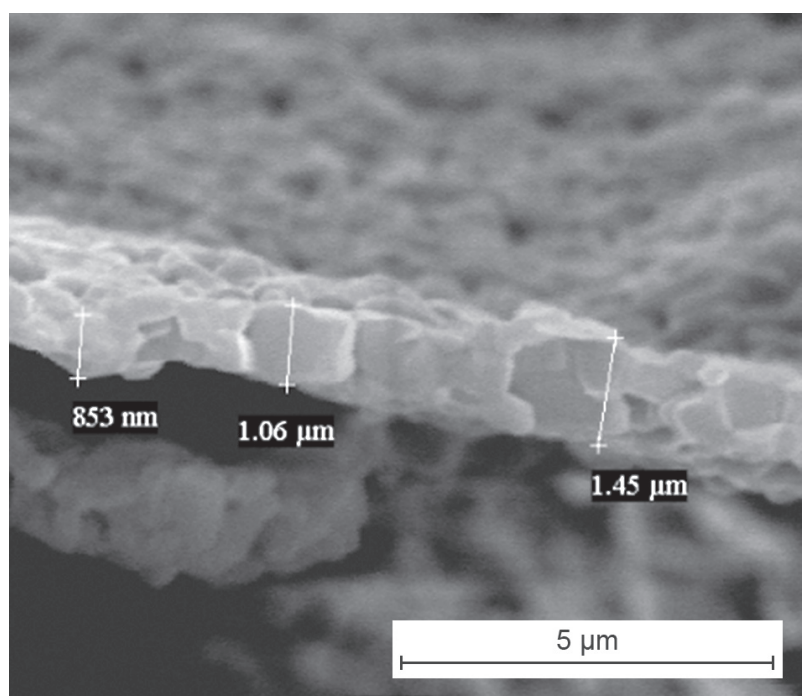

c) $1600^{\circ} \mathrm{C}$

Figure 10. SEM structure of alumina foams sintered at: a) $1450^{\circ} \mathrm{C}$, b) $1550^{\circ} \mathrm{C}, \mathrm{c}$ ) $1600^{\circ} \mathrm{C}$ (arrangement of grains in the lamellas). 


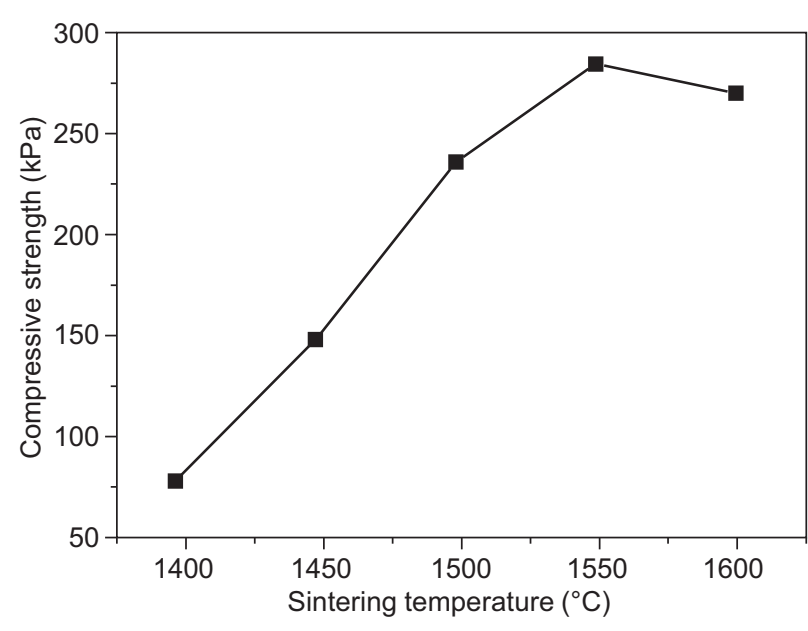

Figure 11. Compressive strength of alumina foams sintered at $1400,1450,1500,1550$ and $1600^{\circ} \mathrm{C}$.

\section{CONCLUSION}

Dodecylbenzenesulfonic acid (DBSA) was applied as a surfactant to prepare alumina foams. Infrared spectroscopy was used to investigate the way of interaction (adsorption) of DBSA on the alumina surface. IR spectra of DBSA and that of alumina - DBSA system were compared. It was found that the sulfonic group of DBSA interacts with the alumina surface. After the adsorption the shift of absorption peaks (1177, 1129, $1035,1007 \mathrm{~cm}^{-1}$ ) which can be attributed to $\mathrm{SO}_{3}$ stretching vibrations was observed and the peaks attributed to the hydrogen bonding disappeared.

The adsorption ability of DBSA onto alumina particles was determined using Lambert-Beer law by measuring UV-VIS spectra. Adsorption of DBSA on the alumina particles was strongly influenced by $\mathrm{pH}$ suspensions. The quantity of DBSA adsorbed on the alumina particles decreased from $75 \%$ to $55 \%$ when the $\mathrm{pH}$ solutions increased from 8.5 to 9.5 . From these results it follows that the probable mechanisms of adsorption were designed:

- $\mathrm{pH}$ < IEP: the specific chemical reactions between the deprotonated sulfonic group of DBSA and the positively charged surface of the alumina can be achieved, the adsorption ability of DBSA is greater than necessary

- $\mathrm{pH} \sim$ IEP: the hydrogen bonding between the deprotonated sulfonic group of DBSA and the neutral alumina surface prevails

- $\mathrm{pH}$ > IEP: the electrostatic repulsion and the weak hydrogen bonding between the deprotonated sulfonic group of DBSA and the negative charged surface of the alumina is present.

The $\mathrm{pH}$ influences the properties of alumina foams to a great extent. With increasing $\mathrm{pH}$, the amount of foam increases during foaming, the bulk density decreases and thus the porosity increases to $97.4 \%$ at $\mathrm{pH} 9.3$. There is a particular $\mathrm{pH}$ range for preparing stable alumina foam. Increasing $\mathrm{pH}$ above 9.5, the foam ratio is too high, thus leading to the destabilization mechanisms of the foam and it collapses. The DBSA does not hydrophobize alumina particles and the DBSA acts only as a surfactant. The foams were sintered at 1400, 1450, 1500, 1550 and $1600^{\circ} \mathrm{C}$. The foams shrunk increased and the porosity decreased from 98.2 to $96.5 \%$ on increasing sintering temperature from $1400^{\circ} \mathrm{C}$ to $1600^{\circ} \mathrm{C}$. The porosity and grains contacting area are the two key factors affecting the compressive strength of alumina foams. The grains of $\mathrm{Al}_{2} \mathrm{O}_{3}$ grew and the compressive strength increased with increasing sintering temperature of the foams. When the foam was sintered at $1600^{\circ} \mathrm{C}$ a few grains grew to larger dimensions compared to that of other grains which caused a decrease of compressive strength.

\section{Acknowledgement}

The work has received the financial support from the Slovak Grant for Science and Technology VEGA No. 1/0503/15 and VEGA No. 1/0696/15.

\section{REFERENCES}

1. Hunter T.N., Pugh R.J., Franks G.V., Jameson G.J. (2008): The role of particles in stabilising foams and emulsions. Advances in Colloid and Interface Science, 137, 57-81. doi:10.1016/j.cis.2007.07.007

2. Paria S., Khilar K.C. (2004): A review on experimental studies of surfactant adsorption at the hydrophilic solidwater interface. Advanced in Colloid and Interface Science, 110, 75-95. doi:10.1016/j.cis.2004.03.001

3. Gao X., Chorover J. (2010): Adsorption of sodium dodecyl sulfate (SDS) at $\mathrm{ZnSe}$ and alpha- $\mathrm{Fe}_{2} \mathrm{O}_{3}$ surfaces: combining infrared spectroscopy and batch uptake studies. Journal of Colloid and Interface Science, 348, 167-176. doi:10.1016/j. jcis.2010.04.011

4. Wang M., Du H., Guo A., Hao R., Hou Z. (2012): Microstructure control in ceramic foams via mixed cationic/anionic surfactant. Materials Letters, 88, 97-100. doi:10.1016/j. matlet.2012.08.028

5. Sun Q., Li Z., Wang J., Li S., Li B., Jiang L., Wang H., Lü Q., Zhang C., Liu W. (2015): Aqueous foam stabilized by partially hydrophobic nanoparticles in the presence of surfactant. Colloids and Surfaces A: Physicochemical and Engineering Aspects, 471, 54-64. doi:10.1016/j.colsurfa. 2015.02.007

6. Huo W.L., Qi F., Zhang X.Y., Ma N., Gan K., Qu Y.N., Xu J., Yang J.L. (2016): Ultralight alumina ceramic foams with single-grain wall using sodium dodecyl sulfate as longchain surfactant. Journal of the European Ceramic Society, 36, 4163-4170. doi:10.1016/j.jeurceramsoc.2016.06.030

7. Li N., Thomas R.K., Rennie A.R. (2012): Effect of pH, surface charge and counter-ions on the adsorption of sodium dodecyl sulfate to the sapphire/solution interface. Journal of Colloid and Interface Science, 378, 152-158. doi:10.1016/j.jcis.2012.04.026 
8. Fu E., Somasundaran P., Maltesh C. (1996): Hydrocarbon and alcohol effects on sulfonate adsorption on alumina. Colloids and Surfaces A: Physicochemical and Engineering Aspects, 112, 55-62. doi:10.1016/0927-7757(96)03540-6

9. Biswas S.C., Chattoraj D.K. (1998): Kinetics of Adsorption of Cationic Surfactants at Silica-Water Interface. Journal of Colloid and Interface Science, 205, 12-20. doi:10.1006/ jcis. 1998.5574

10. Bazelová Z., Pach L., Lokaj J., Kovár V. (2011): Properties of $\mathrm{Al}_{2} \mathrm{O}_{3}$ foams optimized by factorial design. CeramicsSilikáty, 55, 240-245

11. Santhiya D., Subramanian S., Natarajan K.A., Malghan S.G. (2000): Surface chemical studies on alumina suspensions using ammonium poly(methacrylate). Colloids and Surfaces A: Physicochemical and Engineering Aspects, 164, 143-154. doi:10.1016/S0927-7757(99)00347-7

12. Coates J. (2000). Interpretation of Infrared Spectra, a Practical Approach, in: Meyers R.A. (Ed.): Encyclopedia of Analytical Chemistry. John Wiley \& Sons Ltd, pp. 10815-10837

13. Sun B., Zhao Y., Wu J., Yang Q.C., Xu G.X. (1998): Crystal structure and FT-IR study of cesium 4-methylbenzenesulfonate. In Journal of Molecular Structure, 470, 63-66. doi:10.1016/S0022-2860(98)00385-8

14. Deng Y., Wang G., Li N., Guo L. (2009): Synthesis and red-shifted photoluminescence of single-crystalline $\mathrm{ZnO}$ nanowires.JournalofLuminescence, 129,55-58.doi:10.1016/ j.jlumin.2008.07.016

15. Jinnah M.M.A., Umadevi M., Ravikumar B., Ramakrishnan V. (2004): Infrared and laser Raman studies of bis(L-threoninium) sulphate monohydrate. Spectrochimica Acta Part A:
Molecular and Biomolecular Spectroscopy, 60, 2977-2983. doi:10.1016/j.saa.2004.02.010

16. Philip D., Eapen A., Aruldhas G. (1995): Vibrational and Surface Enhanced Raman Scattering Spectra of Sulfamic Acid. Journal of solid state chemistry, 116, 217-223. doi:10.1006/jssc.1995.1206

17. Kim S.G., Kim J.W., Choi H.J., SuhM.S., Shin M.J., Jhon M.S. (2000): Synthesis and electrorheological characterization of emulsion-polymerized dodecylbenzenesulfonic acid doped polyaniline-based suspensions. Colloid and Polymer Science, 278, 894-898. doi:10.1007/s003960000360

18. Chen H., Chang M. (1999): Supramolecular Structure of the Solid-State Complexes of Polyacrylamide and Dodecylbenzenesulfonic Acid. Journal of Polymer Research, 6, 231-236

19. Gonzenbach U.T., Studart A.R., Tervoort E., Gauckler L.J. (2006): Stabilization of Foam with Inorganic Colloidal Particles. Langmuir, 22, 10983-10988. doi:10.1021/la061825a

20. Tang X., Donato A.T. (1996): Aqueous Emulsion Acrylic Binders for Low-Foaming Ceramic Slips. Journal of the American Ceramic Society, 79, 510-512. doi:10.1111/j.11512916.1996.tb08155.x

21. Hidber P.C., Graule T.J., Gauckler L.J. (1997): Influence of the Dispersant Structure on Properties of Electrostatically Stabilized Aqueous Alumina Suspensions. Journal of the European Ceramic Society, 17, 239-249. doi:10.1016/ S0955-2219(96)00151-3

22. Han Y., Li J., Wei Q., Tang K. (2002): The effect of sintering temperatures on alumina foam strength. Ceramics International, 28, 755-759. doi:10.1016/S0272-8842(02) 00039-1 